\title{
Chemical Transformation of $\alpha$-Pinene derived Organosulfate via Heterogeneous OH Oxidation: Implications for Sources and Environmental Fates of Atmospheric Organosulfates
}

5 Rongshuang $\mathrm{Xu}^{1}$, Sze In Madeleine $\mathrm{Ng}^{1}$, Wing Sze Chow ${ }^{2}$, Yee Ka Wong ${ }^{3}$, Yuchen Wang ${ }^{2}$, Donger Lai ${ }^{1}$, Zhongping $\mathrm{Yao}^{4}$, Pui-Kin $\mathrm{So}^{4}$, Jian Zhen $\mathrm{Yu}^{2 *}$, and Man Nin Chan ${ }^{1,5^{*}}$

${ }^{1}$ Earth System Science Programme, Faculty of Science, The Chinese University of Hong Kong, Hong Kong, China

$10 \quad{ }^{2}$ Department of Chemistry, The Hong Kong University of Science and Technology, Hong Kong, China

${ }^{3}$ Division of Environment and Sustainability, The Hong Kong University of Science and Technology, Hong Kong, China

${ }^{4}$ The University Research Facility in Life Sciences, The Hong Kong Polytechnic

15 University, Hong Kong, China

${ }^{5}$ The Institute of Environment, Energy, and Sustainability, The Chinese University of Hong Kong, Hong Kong, China

"Corresponding to: Jian Zhen Yu (jian.yu@ust.hk); Man Nin Chan (mnchan@cuhk.edu.hk)

Abstract.

Organosulfur compounds are found to be ubiquitous in atmospheric aerosols - a majority of which are expected to be organosulfates (OSs). Given the atmospheric abundance of OSs, and their potential to form a variety of reaction products upon ageing, it is imperative 25 to study the transformation kinetics and chemistry of OSs to better elucidate their atmospheric fates and impacts. In this work, we investigated the chemical transformation of an $\alpha$-pinene derived organosulfate $\left(\mathrm{C}_{10} \mathrm{H}_{17} \mathrm{O}_{5} \mathrm{SNa}\right.$, apOS-249) through heterogeneous $\mathrm{OH}$ oxidation at a relative humidity of $50 \%$ in an oxidation flow reactor (OFR). The aerosol-phase reaction products were characterized using the high-performance liquid chromatography-electrospray ionization-high resolution mass spectrometry and the ion chromatography. By monitoring the decay rates of $\alpha$ pOS-249, the effective heterogeneous $\mathrm{OH}$ reaction rate was measured to be $(6.72 \pm 0.55) \times 10^{-13} \mathrm{~cm}^{3}$ molecule $\mathrm{s}^{-1} \mathrm{~s}^{-1}$. This infers an atmospheric lifetime of about two weeks at an average $\mathrm{OH}$ concentration of $1.5 \times 10^{6}$ molecules $\mathrm{cm}^{-3}$. Product analysis shows that $\mathrm{OH}$ oxidation of $\alpha$ pOS-249 can yield more 
oxygenated OSs having a nominal mass-to-charge ratio $(\mathrm{m} / \mathrm{z})$ at $247\left(\mathrm{C}_{10} \mathrm{H}_{15} \mathrm{O}_{5} \mathrm{~S}^{-}\right), 263$ $\left(\mathrm{C}_{10} \mathrm{H}_{15} \mathrm{O}_{6} \mathrm{~S}^{-}\right), 265\left(\mathrm{C}_{10} \mathrm{H}_{17} \mathrm{O}_{6} \mathrm{~S}^{-}\right), 277 \quad\left(\mathrm{C}_{10} \mathrm{H}_{13} \mathrm{O}_{7} \mathrm{~S}^{-}\right), 279\left(\mathrm{C}_{10} \mathrm{H}_{15} \mathrm{O}_{7} \mathrm{~S}^{-}\right)$, and 281 $\left(\mathrm{C}_{10} \mathrm{H}_{17} \mathrm{O}_{7} \mathrm{~S}^{-}\right)$. The formation of fragmentation products, including both small OSs $(\mathrm{C}<10)$ and inorganic sulfates, is found to be insignificant. These observations suggest that functionalization reactions are likely the dominant processes and that multigenerational oxidation possibly leads to formation of products with one or two hydroxyl and carbonyl functional groups adding to $\alpha$ OSS-249. Furthermore, all product ions except $m / z=277$ have been detected in laboratory generated $\alpha$-pinene derived secondary organic aerosols as well as in atmospheric aerosols. Our results reveal that OSs freshly formed from the photochemical oxidation of $\alpha$-pinene could react further to form OSs commonly detected in atmospheric aerosols through heterogeneous $\mathrm{OH}$ oxidation. Overall, this study provides more insights into the sources, transformation, and fate of atmospheric OSs.

\section{Introduction}

Sulfur-containing aerosols are of particular significance for human health because of their high abundance and significant impacts on regional air quality and global climate. The environmental and climatic impacts of inorganic sulfate aerosols such as sulfate are well known. Recently, organosulfur compounds originating from terrestrial, marine, and anthropogenic emissions have also been found to be a significant component of atmospheric aerosols (Tolocka et al., 2012; Huang et al., 2015; Shakya et al., 2013, 2015). Organosulfates (OSs) have been found to be the most important class of organosulfur compounds (Brüggemann et al., 2020), and can greatly affect aerosol formation and growth by varying their surface activity, water uptake, and their ability to serve as cloud condensation nuclei (Hansen et al., 2015; Vogel et al., 2016). Various formation pathways and precursors of OSs have been identified, including biogenic and anthropogenic volatile organic compounds (VOCs) such as isoprene, monoterpenes such as $\alpha$-pinene, $\beta$-pinene, and limonene, oxygenated VOCs, and even aromatic compounds (Iinuma et al., 2005, 2007; Surratt et al., 2008; Kristensen et al., 2011; Zhang et al., 2012; Riva et al., 2015). Given their ubiquity and atmospheric significance, it is crucial to understand the fates and subsequently environmental impacts of OSs. However, although the formation mechanisms of OSs have been relatively well investigated, studies on their transformation are limited to a handful of studies on hydrolysis and heterogeneous oxidation, mechanisms and kinetics are not fully understood. 
Ubiquitous in atmospheric aerosols, OSs have been considered relatively stable over their atmospheric lifetimes and thus used as tracers (Budisulistiorini et al., 2015). Nonetheless, experiments have shown that OSs are prone to transformation via hydrolysis and heterogeneous oxidation by $\mathrm{OH}$. Elrod and co-workers recently reported that OSs can undergo hydrolysis to form polyols and sulfuric acid at rates subject to the aerosol acidity and molecular structure of particular OSs (Darer et al., 2011; Hu et al., 2011). In terms of the structural effects on OS properties and reactivity, they found that tertiary OSs readily undergo hydrolysis at relevant atmospheric aerosol $\mathrm{pH}(0-5)$ (Craig et al., 2018), which are reflected by their starkly shorter chemical lifetimes. Specifically, at $\mathrm{pH}=0$, the lifetimes of tertiary OSs range from only 0.1 day to 19 days, while those of primary and secondary OSs exceed 104 days against hydrolysis. In addition, Hu et al. (2011) discovered that the standard state free energies of hydrolysis for OSs investigated in their work were negative, implying that they are only metastable species and possibly not stable products. work on the heterogeneous OH oxidation of OSs (Kwong et al., 2018; Lam et al., 2019; Chen et al., 2020; Xu et al., 2020a). Transformation of OSs, including methylsulfate, ethylsulfate, and isoprene-derived OSs proceeds at significant rates with a lifetime of about one to two weeks, and the proposed mechanism is that the investigated OSs can be fragmentated into smaller products and sulfate radical anions $\left(\mathrm{SO}_{4}{ }^{-}\right)$, which can participate in further reactions to form inorganic sulfate and other products. Furthermore, while over a hundred OSs have been detected in atmospheric aerosols, many of them are still unidentified, with unknown precursors and formation processes. Currently, reactions whose mechanisms are already understood fail to fully explain the formation of many OSs detected in atmospheric aerosols. Since it is possible for a variety of reaction products to be produced from heterogeneous reactions of OSs, some unidentified OSs (smaller than $\mathrm{C}_{5}$ ) in atmospheric aerosols could be products generated upon further oxidation of OSs (e.g. 2methyltetrol sulfates) formed through the photochemical reactions of VOCs (e.g. isoprene) (Chen et al., 2020). Altogether, previous laboratory findings have prompted the conjecture that the abundance of OSs reported in field studies may have been underestimated if their removal processes have not been properly accounted for. Another significant implication is the urgency to obtain better understanding of the transformation of OSs, which can allow a better assessment of the sources and environmental impacts of atmospheric OSs. 
$\alpha$-pinene is an atmospherically important biogenic VOC, which can undergo photochemical oxidation to form secondary organic aerosols (SOA) (Kanakidou et al., 2005; Pye et al., 2010; Guenther et al., 2012). OSs have been found to be among important constituents of $\alpha$-pinene derived SOA in chamber studies and ambient aerosols (Surratt et 5 al., 2008; Stone et al., 2012; Ma et al., 2014). Field studies reported that a variety of $\alpha-$ pinene derived OSs can contribute $0.6-7.7 \%$ of total sulfate in atmospheric aerosols (Huang et al., 2015, 2018; Wang et al., 2018, 2021). Here, we conducted a laboratory study to investigate the chemical transformation of a model $\alpha$-pinene derived OS (apOS-249, $\mathrm{C}_{10} \mathrm{H}_{17} \mathrm{O}_{5} \mathrm{SNa}$, Sodium 2-hydroxy-2,6,6-trimethylbicyclo [3.1.1] heptan-3-yl sulfate) through heterogeneous $\mathrm{OH}$ oxidation (Table 1). $\alpha$ pOS-249 can be formed through the photooxidation of $\alpha$-pinene in the presence of acidic sulfate aerosols (Surratt et al., 2008). Oxidation experiments were performed using an oxidation flow reactor (OFR) at $50 \% \mathrm{RH}$. After oxidation, aerosols were collected onto Teflon filters for chemical analysis. The composition of reaction products was characterized using the high-performance liquid chromatography-electrospray ionization-high resolution mass spectrometry and the ion chromatography. We first quantify oxidation kinetics by obtaining the effective heterogenous $\mathrm{OH}$ oxidation rate constant based on the decay of $\alpha$ OS-249 against $\mathrm{OH}$ exposure. Second, possible transformation pathways are proposed to explain the formation of the detected products. In particular, we examine whether ambient OSs and inorganic sulfate could be produced upon heterogeneous OH oxidation of apOS-249.

Table 1. Information of the $\alpha$-pinene derived organosulfate investigated in this work.

\begin{tabular}{|c|c|}
\hline Name & $\alpha p O S-249$ \\
\hline Synonyms & $\begin{array}{l}\text { Sodium 2-hydroxy-2,6,6-trimethylbicyclo[3.1.1] } \\
\text { heptan-3-yl sulfate }\end{array}$ \\
\hline Formula & $\mathrm{C}_{10} \mathrm{H}_{17} \mathrm{O}_{5} \mathrm{SNa}$ \\
\hline Molecular weight (g/mol) & 272.29 \\
\hline \multicolumn{2}{|l|}{ Chemical structure $^{a}$} \\
\hline $\begin{array}{c}\text { OH exposure } \\
\left(\times 10^{11} \text { molecule } \mathrm{cm}^{-3} \mathrm{~s}\right)\end{array}$ & $0-17.4$ \\
\hline $\begin{array}{l}\text { Mean surface weighted diameter } \\
\text { prior to oxidation }(\mathrm{nm})\end{array}$ & 181.3 \\
\hline $\begin{array}{l}\text { Effective heterogeneous } \mathrm{OH} \\
\text { reaction rate constant, } k \\
\left(\times 10^{-13} \mathrm{~cm}^{3} \text { molecule } \mathrm{s}^{-1}\right)\end{array}$ & $6.72 \pm 0.55$ \\
\hline Atmospheric lifetime (days) & $11.5 \pm 0.9$ \\
\hline
\end{tabular}

${ }^{a}$ Primary, secondary, and tertiary carbons are circled by red, blue, and green, respectively. 


\section{Experimental Method}

\subsection{Oxidation Experiments}

apOS-249 (in the form of its sodium salt) was synthesized by $\mathrm{Yu}$ and her co-workers (Wang et al., 2017) through the Upjohn dihydroxylation and sulfation of $\alpha$-pinene. The purity ( $\sim 99 \%)$ has been tested using gas chromatography/electron impact-mass spectrometry, liquid chromatography/electrospray ionization-high resolution mass spectrometry and ${ }^{1} \mathrm{H}$ and ${ }^{13} \mathrm{C}$ nuclear magnetic resonance. Heterogeneous $\mathrm{OH}$ oxidation of apOS-249 aerosols was carried out using an OFR at $50 \%$ RH. Experimental details have been given elsewhere (Kang et al., 2007; Xu et al., 2020a). Briefly, $\alpha$ pOS-249 was first dissolved in deionized water $(0.1 \mathrm{wt} \%)$ followed by a 30 -min sonication. Aqueous aerosols were generated by atomizing the solution using an atomizer. The aerosol stream was then mixed with ozone $\left(\mathrm{O}_{3}\right)$, humidified nitrogen $\left(\mathrm{N}_{2}\right)$ and oxygen $\left(\mathrm{O}_{2}\right)$ to control the $\mathrm{RH}$. A total flow of $\sim 5 \mathrm{~L} \mathrm{~min}^{-1}$ was fed into the reactor, corresponding to a residence time of $\sim 156$ s (Xu et al., 2020a).

Gas-phase $\mathrm{OH}$ radicals were generated by photolyzing $\mathrm{O}_{3}$ with UV light at $254 \mathrm{~nm}$ in the presence of water vapor inside the OFR. The concentration of gas-phase $\mathrm{OH}$ radical was varied by changing the $\mathrm{O}_{3}$ concentrations. The $\mathrm{OH}$ exposure, a product of gas-phase $\mathrm{OH}$ radical concentration and the residence time, ranged from $0-17.4 \times 10^{11}$ molecule $\mathrm{cm}^{-3}$ $\mathrm{s}$ and was determined by measuring the decay of sulfur dioxide $\left(\mathrm{SO}_{2}\right)$ in independent calibrating experiments in the presence or absence of apOS-249 aerosols (Kang et al., 2007). It acknowledges that the presence of aerosols did not significantly affect the generation of gas-phase $\mathrm{OH}$ radicals and the determination of $\mathrm{OH}$ exposure (less than $\sim 10$ $\%)$. After removing residual $\mathrm{O}_{3}$ and gas-phase species from the gas stream leaving the reactor, the size distribution of the aerosols were measured by a scanning mobility particle sizer. Before oxidation, the mean surface weighted diameter for aerosol distribution was about $181 \pm 0.5 \mathrm{~nm}$ with a geometric standard deviation of 1.3 and the aerosol mass loading was $\sim 2000 \mu \mathrm{g} \mathrm{m}^{-3}$. Aerosols were also collected onto the Teflon filters for $30 \mathrm{~min}$. with a total gas sampling volume of $\sim 90 \mathrm{~L}$. Duplicate filters were collected from each of oxidation experiments for subsequent chemical analysis. After collection, filters were immediately stored at $-20 C^{\circ}$ in the dark and analyzed within 3 months.

\subsection{Chemical Characterization of $\alpha$ OSOS-249 and OSs formed upon Oxidation}

Scheme S1 shows the overview of the chemical analysis. First, the filters were 
filtered through a $0.2 \mu \mathrm{m}$ polytetrafluoroethylene (PTFE) syringe filter and combined. 300 $\mu \mathrm{L}$ of the extract was blown to dryness under a gentle stream of $\mathrm{N}_{2}$ at room temperature and then reconstituted in $1 \mathrm{~mL}$ methanol-water (1:1 vol/vol) containing $200 \mathrm{ppb} \mathrm{D}_{17-\mathrm{octyl}}$ sulfate as an internal standard.

2.2.1 HPLC/ESI-QToF-MS: To characterize the reaction products (i.e. OSs), $5 \mu \mathrm{L}$ of reconstituted extract was injected into an Agilent 1290 UHPLC system equipped with an ESI source interfaced to an Agilent 6540 Quadrupole-Time-of-Flight Mass Spectrometer (HPLC/ESI-QToF-MS). Experimental details have been given elsewhere 10 (Wang et al., 2017, 2021). Sample injections were first separated using an Acquity UPLC HSS T3 column ( $2.1 \mathrm{~mm} \times 100 \mathrm{~mm}, 1.8 \mu \mathrm{m}$; Waters, Milford, MA) with mobile phase consisting of water $\left(\mathrm{H}_{2} \mathrm{O}\right)$ (eluent $\mathrm{A}$ ) and methanol (eluent $\mathrm{B}$ ), each containing $0.1 \%$ formic

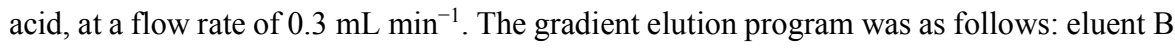
initially was set at $5 \%$ for $2.0 \mathrm{~min}$, increased to $95 \%$ in $10.0 \mathrm{~min}$, and held for $2 \mathrm{~min}$; then decreased to $5 \%$ in the next $0.1 \mathrm{~min}$ and held for $2.9 \mathrm{~min}$. The ESI source was operated in the negative ion mode under following parameters: $2.8 \mathrm{kV}$ for capillary voltage, $120 \mathrm{~V}$ for fragment, $320{ }^{\circ} \mathrm{C}$ for sheath gas temperature, $8 \mathrm{~L} \mathrm{~min}^{-1}$ for drying gas flow and 45 psi for nebulizer pressure. Mass spectra were recorded across the range $m / z 50-1000$ at $4 \mathrm{GHz}$ with a resolution of 40,000 FWHM. The $\mathrm{MS}^{2}$ spectra were also acquired at a collision energy of $13 \mathrm{eV}$ to validate whether these ions are OSs by sulfur-containing fragments: $\mathrm{SO}_{3}{ }^{-\bullet}(\mathrm{m} / z=79.9574), \mathrm{HSO}_{3}{ }^{-}(\mathrm{m} / z=80.9651), \mathrm{SO}_{4}{ }^{-}(\mathrm{m} / \mathrm{z}=95.9523)$ and $\mathrm{HSO}_{4}{ }^{-}(\mathrm{m} / \mathrm{z}=$ 96.9601) (Surratt et al., 2008; Hettiyadura et al., 2017). Data were analyzed using Mass Hunter Qualitative software (version B.07.00 Agilent Technologies).

2.2.2 HPLC/ESI-QTRAP-MS: To quantify the amount of $\alpha$ pOS-249 before and after oxidation, $5 \mu \mathrm{L}$ of reconstituted extract was injected into an Agilent $1260 \mathrm{LC}$ system (Palo Alto, CA) interfaced with a QTRAP 4500 mass spectrometer (AB Sciex, Toronto, Ontario, Canada) and a TurbolonSpray source operated in multiple reaction monitoring (MRM) mode (Wang et al., 2017, 2021). LC separation was preformed using the same column and mobile phase adopted for HPLC/ESI-QToF-MS. The gradient elution program was set to be: eluent B initially was set at $1 \%$ for $2.7 \mathrm{~min}$, increased to $54 \%$ in $17.9 \mathrm{~min}$, and held for $1 \mathrm{~min}$; then increased to $90 \%$ in the next $7.5 \mathrm{~min}$ and held for $0.2 \mathrm{~min}$; and finally decreased to $1 \%$ in $1.8 \mathrm{~min}$ and held for $9.3 \mathrm{~min}$. Table S1 shows the parameters optimized for the mass transition between the deprotonated molecular ion of $\alpha \mathrm{pOS}-249\left(\mathrm{C}_{10} \mathrm{H}_{17} \mathrm{O}_{5} \mathrm{~S}^{-}\right)$ and bisulfate ion $\left(\mathrm{HSO}_{4}{ }^{-}\right)$. The transition was set to have a dwell time of $100 \mathrm{~ms}$. The scan 
rate was 200 Da per s. Calibration curve was generated using $\alpha$ pOS-249 standard solution (retention time $=17.8 \mathrm{~min}$ ) with $200 \mathrm{ppb} \mathrm{D}_{17}$-octyl sulfate as an internal standard. The extraction efficiency of apOS-249 was determined to be $85.3 \pm 3.4 \%$ by measuring the recovery of apOS-249 standard spiked into blank filters. The uncertainty associated with the quantification of $\alpha$ pOS-249 is discussed in the Supporting Information.

\subsection{Quantification of Inorganic Sulfate formed upon Oxidation}

The amount of inorganic sulfate $\left(\mathrm{SO}_{4}{ }^{2-}\right)$ formed upon oxidation was quantified using IC method. Operating conditions have been given by Huang et al. (2018). Briefly, the filters were extracted using $5 \mathrm{~mL}$ of double de-ionized water $(18.2 \mathrm{M} \Omega \mathrm{cm})$ from the ultrapure water system (Nanopure Diamond UV/UF) and were sonicated for $60 \mathrm{~min}$ and then mechanically shaken for $60 \mathrm{~min}$. After filtering, these extracts were subsequently analyzed by an ion chromatograph (Dionex ICS-1100). The separation of anions was accomplished using an AS11-HC analytical column (IonPac, $4 \times 250 \mathrm{~mm}$ ) and an AG11-HC guard column (IonPac, $4 \times 50 \mathrm{~mm}$ ) with $15 \mathrm{mmol} \mathrm{L}^{-1} \mathrm{NaOH}$ eluent. It is known that bisulfate ion $\left(\mathrm{HSO}_{4}{ }^{-}\right)$is being converted into $\mathrm{SO}_{4}{ }^{2-}$ upon mixing with the alkaline eluent. The concentration of $\mathrm{SO}_{4}{ }^{2-}$ quantified by the IC method thus represents a total amount of $\mathrm{HSO}_{4}{ }^{-}$ and $\mathrm{SO}_{4}{ }^{2-}$. Our pervious study has shown that the peak from the $\mathrm{Na}_{2} \mathrm{SO}_{4}$ standard has the same retention time in the IC chromatogram as that of the sodium bisulfate $\left(\mathrm{NaHSO}_{4}\right)$ standard (Xu et al., 2020a). Furthermore, the responses of the $\mathrm{NaHSO}_{4}$ and $\mathrm{Na}_{2} \mathrm{SO}_{4}$ standards are about the same. These would justify the use of the $\mathrm{Na}_{2} \mathrm{SO}_{4}$ standard for the quantification of $\mathrm{HSO}_{4}{ }^{-}$and $\mathrm{SO}_{4}{ }^{2-}$. In this work, the amount of $\mathrm{HSO}_{4}{ }^{-}$and/or $\mathrm{SO}_{4}{ }^{2-}$ produced upon oxidation at a given $\mathrm{OH}$ exposure was proportional to its peak area in the chromatogram and was determined using the $\mathrm{Na}_{2} \mathrm{SO}_{4}$ standard calibration curve. The extraction efficiency was determined to be $90.3 \pm 1.5 \%$ by measuring the recovery of the $\mathrm{Na}_{2} \mathrm{SO}_{4}$ standard spiked onto blank filters. The uncertainty for the measurement of $\mathrm{SO}_{4}{ }^{2-}$ is discussed in the Supporting Information.

We also note that no distinct peak was detected in the ion chromatogram for apOS-

30249 standard while a small peak corresponding to $\mathrm{SO}_{4}{ }^{2-}$ was observed. The absence of apOS-249 peak could attribute to that IC detection for ionic and ionizable species is likely to be limited to small compounds (up to $C_{5}$ ) (Surratt et al., 2008; Domingos et al., 2012). The presence of $\mathrm{SO}_{4}{ }^{2-}$ peak may be due to the hydrolysis of $\alpha \mathrm{pOS}-249$. However, this peak comprised $2.1 \pm 0.8 \%$ of the total mass, suggesting that the hydrolysis of apOS-249 was 
not significant. This observation is consistent with the literature that $\alpha \mathrm{pOS}-249$ does not readily undergo hydrolysis (Hu et al., 2015).

The high recovery of apOS-249 suggests the extraction methods are effective and apOS-249 is relatively stable under our experimental conditions. Wang et al. (2017) have also reported that there was no degradation after two-years' storage at low temperature ($20{ }^{\circ} \mathrm{C}$ ) for $\alpha$ pOS-249. A recent study by Hughes et al. (2019) have examined the stability of a range of OSs (e.g. methyl sulfate, hydroxyacetone sulfate, two $\alpha$-pinene derived OSs: $m / z=279\left(\mathrm{C}_{10} \mathrm{H}_{15} \mathrm{O}_{7} \mathrm{~S}^{-}\right)$, and $\left.m / z=281\left(\mathrm{C}_{10} \mathrm{H}_{17} \mathrm{O}_{7} \mathrm{~S}^{-}\right)\right)$on filters frozen at $-20{ }^{\circ} \mathrm{C}$ over one year. The filters were extracted via similar procedure applied in this study and the extracts were analyzed by HPLC-ESI-HRMS. They found that the investigated OSs with different functional groups (e.g. alkyl, carboxylate, and hydroxyl groups) showed no degradation during the storage. Taken together, $\alpha \mathrm{pOS}-249$ and its oxidation products (i.e. OSs) which have similar carbon skeletons while possessing different functional groups (alcohol and/or ketone) are expected to be stable during the storage and pre-treatment processes for chemical analysis.

\section{Results and Discussion}

Fig. 1 shows the total ion chromatogram (TIC) characterized by HPLC/ESI-QToFMS for the OH oxidation of apOS-249. Before oxidation (Fig. 1a), a single dominant peak corresponds to the deprotonated molecular ion $\left([\mathrm{M}-\mathrm{H}]^{-}\right)$of $\alpha$ pOS-249 $(\mathrm{m} / z=249$, $\left.\mathrm{C}_{10} \mathrm{H}_{17} \mathrm{O}_{5} \mathrm{~S}^{-}\right)$. Upon oxidation at an $\mathrm{OH}$ exposure of $17.4 \times 10^{11}$ molecules $\mathrm{cm}^{-3} \mathrm{~s}$ (Fig. 1b), apOS-249 remains the dominant peak, accompanied by the appearance of some new product peaks in small intensity relative to apOS-249. Fig. 2 shows the extracted ion chromatograms (EICs) of the ions that are observed in the chromatograms after oxidation. Six product ions are detected upon oxidation and correspond to $m / z=247\left(\mathrm{C}_{10} \mathrm{H}_{15} \mathrm{O}_{5} \mathrm{~S}^{-}\right)$, $263\left(\mathrm{C}_{10} \mathrm{H}_{15} \mathrm{O}_{6} \mathrm{~S}^{-}\right), 265\left(\mathrm{C}_{10} \mathrm{H}_{17} \mathrm{O}_{6} \mathrm{~S}^{-}\right), 277\left(\mathrm{C}_{10} \mathrm{H}_{13} \mathrm{O}_{7} \mathrm{~S}^{-}\right), 279\left(\mathrm{C}_{10} \mathrm{H}_{15} \mathrm{O}_{7} \mathrm{~S}^{-}\right)$, and 281 $\left(\mathrm{C}_{10} \mathrm{H}_{17} \mathrm{O}_{7} \mathrm{~S}^{-}\right)$. A mass tolerance was set to less than \pm 5 ppm for assigning the chemical formula of the detected ions. On the basis of the chemical formulas, the ions that are detected are suggested to be OSs (Table 2). As shown in Fig. S1, $\mathrm{MS}^{2}$ spectra show these ions fragmented into sulfur containing ions $\left(\mathrm{SO}_{3}{ }^{-\bullet}(\mathrm{m} / \mathrm{z}=79.9574), \mathrm{HSO}_{3}{ }^{-}(\mathrm{m} / \mathrm{z}=80.9651)\right.$, and $\left.\mathrm{HSO}_{4}^{-}(\mathrm{m} / \mathrm{z}=96.9601)\right)$ and further confirmed the identity of these ions are OSs (Surratt et al., 2008; Hettiyadura et al., 2017; Wang et al., 2017, 2021). It may not be surprising that $\mathrm{SO}_{4}^{-\cdot}(m / z=95.9523)$ was not observed in these $\mathrm{MS}^{2}$ spectra since it is likely 

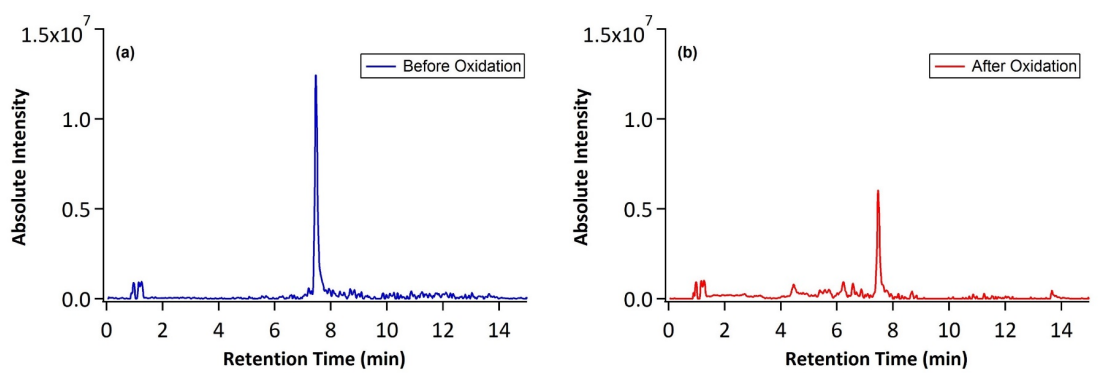

Figure 1. The total ion chromatograms (TIC) characterized by HPLC/ESI-QToF-MS before and after heterogeneous $\mathrm{OH}$ oxidation of apOS-249.

Control experiments were also conducted to investigate the effects of $\mathrm{O}_{3}$ and $\mathrm{UV}$ light on $\alpha$ pOS-249. Fig. S2 shows that the impacts of UV photolysis and $\mathrm{O}_{3}$ reactivity on $\alpha$ pOS249 are not significant (less than $5 \%$ change in the apOS-249 signal in UV only and $\mathrm{O}_{3}$ only experiments). Similar results have been observed for other OSs (e.g. methylsulfate, ethylsulfate, 2-methyltetrol sulfate, and 3-methyltetrol sulfate) that these OSs do not react

10 with $\mathrm{O}_{3}$ and photolyze at $\mathrm{UV}=254 \mathrm{~nm}$ (Kwong et al., 2018; Lam et al., 2019; Chen et al., 2020; Xu et al., 2020a). 
Table 2. Comparison of reaction products formed upon heterogeneous $\mathrm{OH}$ oxidation of $\alpha \mathrm{pOS}$ 249 with the laboratory and field studies.

\begin{tabular}{|c|c|c|c|c|c|}
\hline \multirow[b]{2}{*}{$\begin{array}{l}\text { Chemical } \\
\text { formula } \\
{[\mathrm{M}-\mathrm{H}]^{-}} \\
\text {(theoretical } \\
\text { mass) }\end{array}$} & \multicolumn{2}{|c|}{ This work } & \multicolumn{3}{|c|}{ Previous studies } \\
\hline & $\begin{array}{l}\text { Retention } \\
\text { time } \\
(\min )^{\mathrm{a}}\end{array}$ & $\begin{array}{l}\text { Detected } \\
\text { mass } \\
(\text { error })^{\mathrm{a}}\end{array}$ & $\begin{array}{c}\text { Ambient } \\
\text { mean } \\
\text { concentration } \\
\left(\mathrm{ng} \mathrm{m}^{-3}\right)\end{array}$ & $\begin{array}{l}\text { Laboratory } \\
\text { experiment }\end{array}$ & $\begin{array}{c}\text { Suggested } \\
\text { chemical } \\
\text { structure } \\
\text { reported in the } \\
\text { literature }\end{array}$ \\
\hline $\begin{array}{l}\mathrm{C}_{10} \mathrm{H}_{15} \mathrm{O}_{5} \mathrm{~S}^{-} \\
(247.0646)\end{array}$ & 6.860 & $\begin{array}{c}247.0648 \\
(0.8095)\end{array}$ & $3.32^{\mathrm{b}}$ & $\begin{array}{l}\text { a-pinene } \\
\text { OH/high-NOx/ } \\
\text { highly acidic } \\
\text { sulfate aerosols }\end{array}$ & Not known \\
\hline $\begin{array}{l}\mathrm{C}_{10} \mathrm{H}_{15} \mathrm{O}_{6} \mathrm{~S}^{-} \\
(263.0595)\end{array}$ & $\begin{array}{l}4.992 ; \\
5.479 ; \\
5.787 ; \\
6.028 ; \\
6.227\end{array}$ & $\begin{array}{c}263.0600 \\
(1.9007)\end{array}$ & $0.114^{b}$ & Not observed & Not known \\
\hline $\begin{array}{l}\mathrm{C}_{10} \mathrm{H}_{17} \mathrm{O}_{6} \mathrm{~S}^{-} \\
(265.0751)\end{array}$ & $\begin{array}{l}3.283 ; \\
4.798 ; \\
5.420 ; \\
6.269 ; \\
6.408 ; \\
\mathbf{6 . 5 6 3} ; \\
6.740\end{array}$ & $\begin{array}{c}265.0762 \\
(4.1498)\end{array}$ & $0.076^{\mathrm{b}}$ & 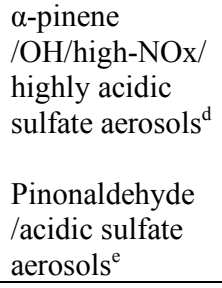 & \\
\hline $\begin{array}{l}\mathrm{C}_{10} \mathrm{H}_{13} \mathrm{O}_{7} \mathrm{~S}^{-} \\
(277.0387)\end{array}$ & 6.117 & $\begin{array}{c}277.0399 \\
(4.3315)\end{array}$ & Not observed & Not observed & Not known \\
\hline $\begin{array}{l}\mathrm{C}_{10} \mathrm{H}_{15} \mathrm{O}_{7} \mathrm{~S}^{-} \\
(279.0544)\end{array}$ & $\begin{array}{l}4.916 ; \\
5.384 \\
5.551 \\
5.698 \\
\end{array}$ & $\begin{array}{c}279.0545 \\
(0.3584)\end{array}$ & $7.1^{\mathrm{c}}$ & $\begin{array}{l}\alpha \text {-pinene } \\
/ \mathrm{OH} / \text { high-NOx/ } \text { highly acidic } \\
\text { sulfate aerosols }\end{array}$ & \\
\hline $\begin{array}{l}\mathrm{C}_{10} \mathrm{H}_{17} \mathrm{O}_{7} \mathrm{~S}^{-} \\
(281.0700)\end{array}$ & 4.452 & $\begin{array}{c}281.0709 \\
(3.2020)\end{array}$ & $12.1^{\mathrm{c}}$ & 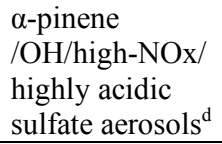 & \\
\hline
\end{tabular}

${ }^{a}$ The retention time in bold corresponds to the major peak in each EIC and only corresponding detected mass with mass errors (calculated in ppm) for these major peaks are listed for

5 simplification. ${ }^{\mathrm{b}}$ These values were measured by the HPLC-triple quadrupole(TQ)-MS using sodium octyl sulfate as surrogate for quantification (Ma et al., 2014). ${ }^{c}$ These values were measured by the HPLC- triple quadrupole(TQ)-MS using hydroxyacetone sulfate as surrogate for quantification (Hettiyadura et al., 2019). ${ }^{\mathrm{d}}$ Same ion has been detected in the $\alpha$-pinene derived SOA formed from the photochemical oxidation of $\alpha$-pinene in chamber studies (Surratt

10 et al., 2008; Ma et al., 2014). ${ }^{\text {e }}$ Same ion has been detected in the reactive uptake of pinonaldehyde on acidic sulfate aerosols (Liggio et al., 2006). ${ }^{\mathrm{f}}$ Chemical structure proposed by Liggio et al. (2006). ${ }^{\mathrm{g}}$ Chemical structure proposed by Surratt et al. (2008). ${ }^{\mathrm{h}}$ Chemical structure proposed by Hettiyadura et al. (2019). 

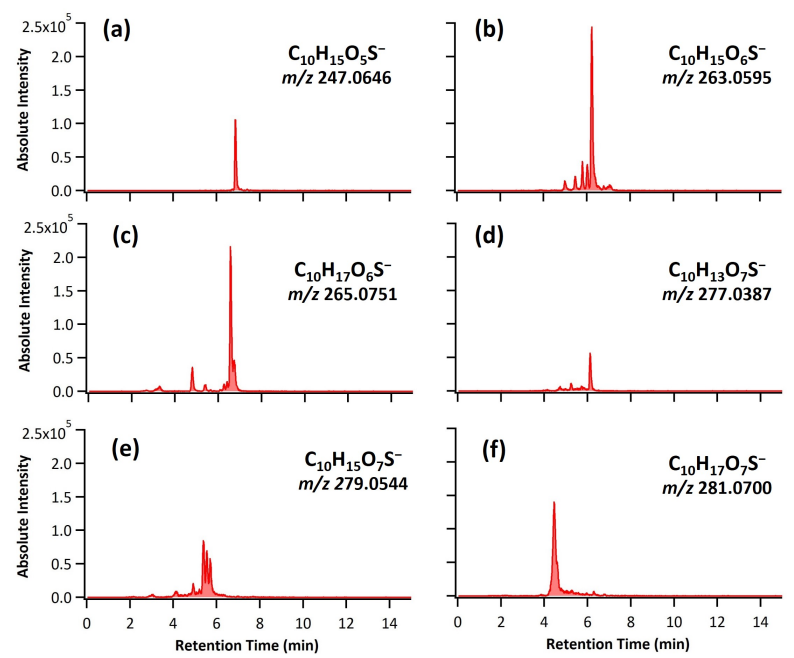

Figure 2. The extracted ion chromatograms (EICs) of the ions associated with reaction products formed upon heterogeneous OH oxidation of $\alpha$ POS-249 at the highest OH exposure by HPLC/ESIQToF-MS with mass tolerance of \pm 5 ppm to their theoretical masses (shown).

\subsection{Oxidation Kinetics}

As shown in Fig. 3, apOS-249 decays at a significant rate upon oxidation. Approximately 30 $\%$ of $\alpha$ pOS-249 remains unreacted at the highest $\mathrm{OH}$ exposure. Oxidation kinetics can be quantified by measuring the decay of $\alpha$ pOS-249 at different $\mathrm{OH}$ exposures. The normalized decay can be fit with an exponential function (Smith et al., 2009):

$$
\ln \frac{I}{I_{0}}=-k[\mathrm{OH}] \cdot t
$$

where $I$ is the concentration of apOS-249 quantified by HPLC/ESI-QTRAP-MS at a given $\mathrm{OH}$ exposure, $I_{0}$ is the concentration before oxidation, $k$ is the effective second-order heterogeneous $\mathrm{OH}$ rate constant and $[\mathrm{OH}] \cdot t$ is the $\mathrm{OH}$ exposure. The rate constant determined using Eq. 1 is

15 found to be $(6.72 \pm 0.55) \times 10^{-13} \mathrm{~cm}^{3}$ molecule $\mathrm{e}^{-1} \mathrm{~s}^{-1}$. Assuming a $24-\mathrm{h}$ averaged $[\mathrm{OH}]$ of $1.5 \times 10^{6}$ molecules $\mathrm{cm}^{-3}$ (Mao et al., 2009), the atmospheric lifetime of $\alpha$ OS-249 against heterogeneous $\mathrm{OH}$ oxidation, $\tau=1 / k[\mathrm{OH}]$ is calculated to be $11.5 \pm 0.9$ days. Considering atmospheric aerosols with a similar size $(\sim 200 \mathrm{~nm})$ having a typical lifetime of 10-14 days against wet/dry deposition (Kanakidou et al., 2005), heterogeneous OH oxidation could be a competitive sink for apOS-249.

20 Lam et al. (2018) and Chen et al. (2020) recently reported that isoprene-derived OSs (i.e. 2methyltetrol sulfate and 3-methyltetrol sulfate) can undergo heterogeneous $\mathrm{OH}$ oxidation efficiently. Altogether, these results may suggest that transformation kinetics and pathways would need to be considered in chemical transport models in order to better predict the abundance and composition of atmospheric OSs. 


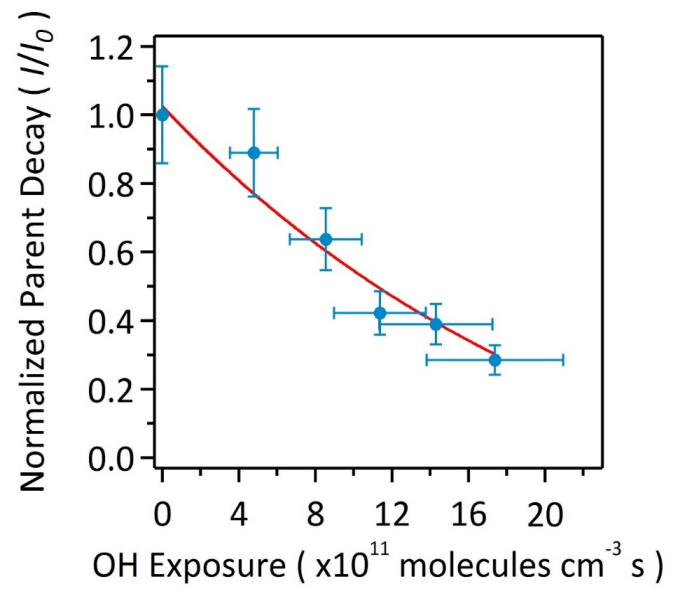

Figure 3. The normalized decay of apOS-249 upon heterogeneous $\mathrm{OH}$ oxidation.

\subsection{Reaction Mechanism}

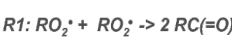
$R 2: \mathrm{RO}_{2} \cdot+\mathrm{RO}_{2} \cdot \rightarrow \mathrm{RC}(=\mathrm{O})+\mathrm{ROH}$ $R 3: \mathrm{RO} \cdot+\mathrm{O}_{2} \rightarrow \mathrm{R}(=\mathrm{O})+\mathrm{HO}_{2}$ R4: $R O \cdot+R H \rightarrow R O H+R$ R5: $R O^{\circ} \cdot>$ decomposition
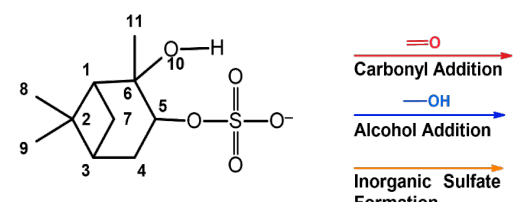

Formation

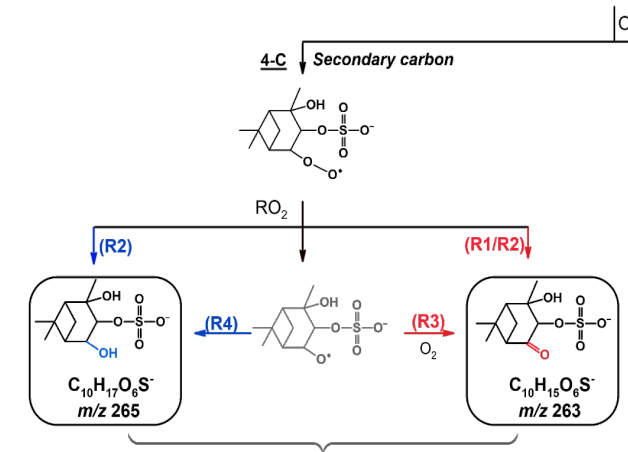

$\mathrm{OH}, \mathrm{O}_{2}$ Tertiary carbon, $\underline{\text { 5-C }}$

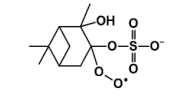

$\mathrm{RO}_{2}$
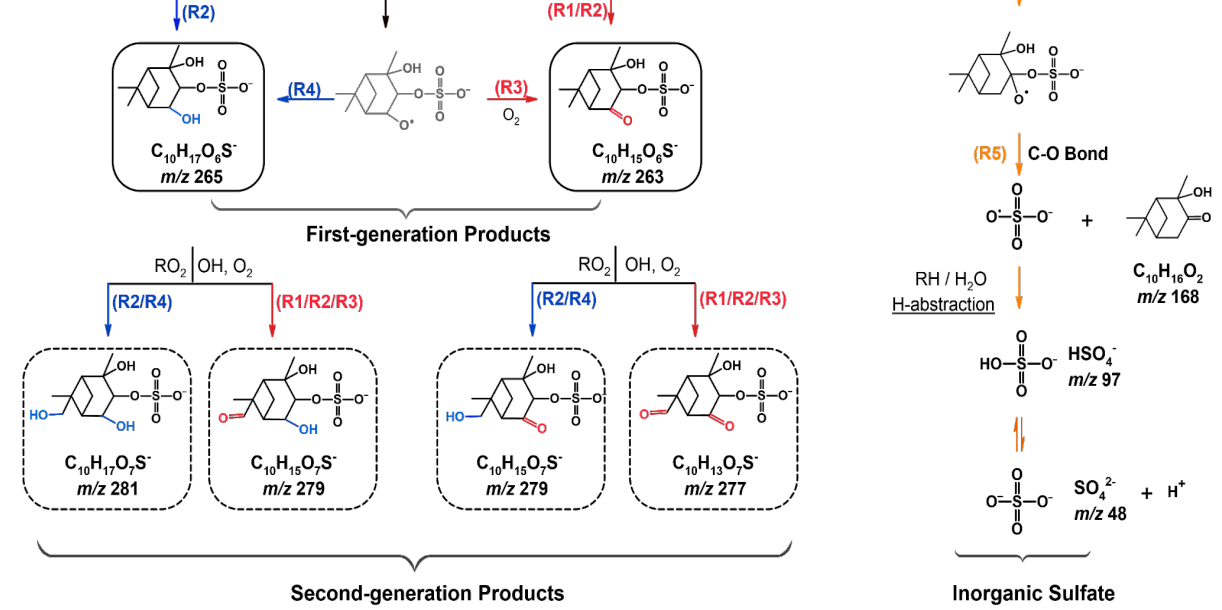

Inorganic Sulfate

Scheme 1. Formation mechanisms tentatively proposed for the formation of more oxygenated $\mathrm{C}_{10}$ OSs and inorganic sulfate upon heterogeneous OH oxidation of $\alpha$ POS-249. 
Scheme 1 shows the proposed formation pathways for the detected products summarized in Table 2. Prior to oxidation, $\alpha \mathrm{pOS}-249$ tends to dissociate readily. Oxidation is initiated via hydrogen abstraction by an $\mathrm{OH}$ radical, forming an alkyl radical $(\mathrm{R} \bullet)$, which reacts with an oxygen $\left(\mathrm{O}_{2}\right)$ molecule quickly to form a peroxy radical $\left(\mathrm{RO}_{2} \bullet\right)$, which can react via different pathways. For instance, the reactions of two $\mathrm{RO}_{2} \bullet$ can generate two carbonyl products via Bennett and Summers mechanism (R1) (Bennett and Summers, 1974), an alcohol product and a carbonyl product via Russell reactions (R2) (Russell, 1957), or two alkoxy radicals (RO•). $\mathrm{RO} \bullet$ can react with an $\mathrm{O}_{2}$ molecule (R3), undergo intermolecular hydrogen abstraction (R4), and/or decompose involving the cleavage of a C-C bond or a C-O bond (George and Abbatt, 2008; Carrasquillo et al., 2015; Kroll et al., 2015).

$$
\begin{gathered}
\mathrm{RO}_{2} \bullet+\mathrm{RO}_{2} \bullet \rightarrow 2 \mathrm{R}(=\mathrm{O})(\mathbf{R} 1) \\
\mathrm{RO}_{2} \bullet+\mathrm{RO}_{2} \bullet \rightarrow \mathrm{R}(=\mathrm{O})+\mathrm{ROH}(\mathbf{R} 2) \\
\mathrm{RO}_{2} \bullet+\mathrm{RO}_{2} \bullet \rightarrow 2 \mathrm{RO} \bullet \\
\mathrm{RO} \bullet+\mathrm{O}_{2} \rightarrow \mathrm{R}(=\mathrm{O})+\mathrm{HO}_{2}(\mathbf{R} 3) \\
\mathrm{RO} \bullet+\mathrm{R}^{\prime} \mathrm{H} \rightarrow \mathrm{ROH}+\mathrm{R}^{\prime} \bullet(\mathbf{R 4}) \\
\mathrm{RO} \bullet \rightarrow \text { decomposition (R5) }
\end{gathered}
$$

Based on detected products (Table 2 and Fig. 2), $\mathrm{OH}$ oxidation tends to increase the functionalities and oxygen content of apOS-249. Moreover, these products $\left(\mathrm{C}_{10} \mathrm{OSs}\right)$ can be classified as functionalization products and are formed via the addition of one or two oxygenated functional groups to $\alpha \mathrm{pOS}-249$. For instance, ions corresponding to first-generation products produced from $\mathrm{OH}$ oxidation of $\alpha$ pOS-249 are detected at $m / z=263\left(\mathrm{C}_{10} \mathrm{H}_{15} \mathrm{O}_{6} \mathrm{~S}^{-}\right)$and 265 $\left(\mathrm{C}_{10} \mathrm{H}_{17} \mathrm{O}_{6} \mathrm{~S}^{-}\right)$. When the oxidation proceeds, these products can react with $\mathrm{OH}$ radicals to form second-generation products, which give $m / z=277\left(\mathrm{C}_{10} \mathrm{H}_{13} \mathrm{O}_{7} \mathrm{~S}^{-}\right), 279\left(\mathrm{C}_{10} \mathrm{H}_{15} \mathrm{O}_{7} \mathrm{~S}^{-}\right)$, and 281 $\left(\mathrm{C}_{10} \mathrm{H}_{17} \mathrm{O}_{7} \mathrm{~S}^{-}\right)$products.

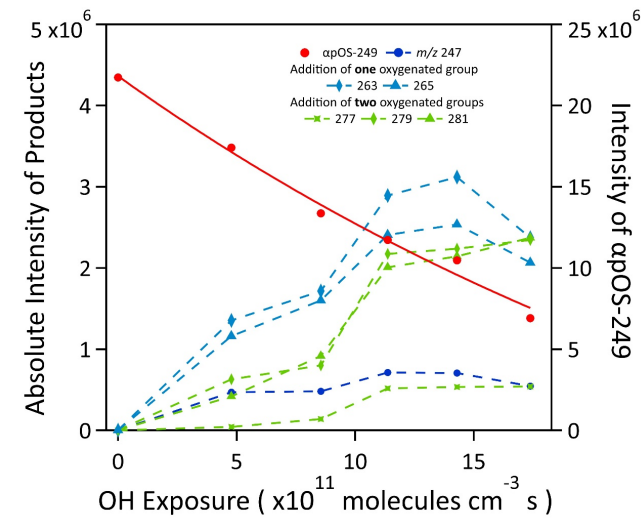

Figure 4. The evolution in the signal intensity of the reaction products formed upon the heterogeneous $\mathrm{OH}$ oxidation of $\alpha \mathrm{pOS}-249$ as a function of $\mathrm{OH}$ exposure. 


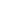

Fig. 4 shows the evolution of the intensity of the reaction products as a function of $\mathrm{OH}$ exposure. Different kinetic profiles have been observed for first- and second-generation products. It can be seen that first-generation products $\left(m / z=263\left(\mathrm{C}_{10} \mathrm{H}_{15} \mathrm{O}_{6} \mathrm{~S}^{-}\right)\right.$and $\left.265\left(\mathrm{C}_{10} \mathrm{H}_{17} \mathrm{O}_{6} \mathrm{~S}^{-}\right)\right)$reach a maximum intensity at an $\mathrm{OH}$ exposure of about $14.3 \times 10^{11}$ molecules $\mathrm{cm}^{-3} \mathrm{~s}$. Their intensities then decrease slightly at the highest $\mathrm{OH}$ exposure. The concentration of second-generation products $\left(m / z=277\left(\mathrm{C}_{10} \mathrm{H}_{13} \mathrm{O}_{7} \mathrm{~S}^{-}\right), 279\left(\mathrm{C}_{10} \mathrm{H}_{15} \mathrm{O}_{7} \mathrm{~S}^{-}\right)\right.$, and $\left.281\left(\mathrm{C}_{10} \mathrm{H}_{17} \mathrm{O}_{7} \mathrm{~S}^{-}\right)\right)$follows a different kinetic profile. At low $\mathrm{OH}$ exposures, the intensities of the products are observed to increase at a slightly slower rate relative to first-generation products. Their concentrations always increase with increasing $\mathrm{OH}$ exposure and reach their maximum values at the highest $\mathrm{OH}$ exposure. This trend

10 is consistent with the multigenerational reactions that the formation of second-generation products is from the reactions of $\mathrm{OH}$ with first-generation products. In general, the products detected, shown in Table 2, are consistent with reactions (described in detail below) that form hydroxyl and carbonyl functional groups.

15 During oxidation, the carbon site where the hydrogen atom is abstracted by $\mathrm{OH}$ radical governs the following formation of products. More recently, molecular dynamics (MD) simulations showed that heterogeneous reaction is likely not initiated by the direct collision between a gasphase $\mathrm{OH}$ radical and an organic molecule near the aerosol surface (Xu et al., 2020b; Lam et al., 2021). Instead, the reaction may occur after a number of collisions between the absorbed $\mathrm{OH}$ radical

20 and the organic molecule. As a first approximation, the reactivity of $\alpha$ pOS-249 towards OH radical is estimated by a structure-activity relationship (SAR) model proposed for aqueous-phase $\mathrm{OH}$ reactions with organic compounds (Monod and Doussin, 2008). We acknowledge that the SAR model does not include the parameterization of the sulfate group $\left(-\mathrm{OSO}_{3}{ }^{-}\right)$for OSs. As the sulfate group $\left(-\mathrm{OSO}_{3}{ }^{-}\right)$exhibits a resonance electron-withdrawing effect (Bahl et al., 2012) as the

25 carboxylate anion $\left(-\mathrm{COO}^{-}\right)$and bears a negative charge, here the effect of the sulfate group on the $\mathrm{OH}$ reactivity is evaluated using the descriptor of the carboxylate anion $\left(-\mathrm{COO}^{-}\right)$in the SAR model. Overall, the goal of this simple analysis is to qualitatively assess which carbon site is more favorable for hydrogen abstraction in reactions of OH radical with $\alpha$ pOS-249 in order to gain more insights into the reaction mechanisms.

Table S2 shows the reactivity of hydrogen atom at different reaction sites upon $\mathrm{OH}$ oxidation of apOS-249. The model predicts that the hydrogen abstraction is likely occurred at two secondary carbons (4-C and 7-C) and a tertiary carbon (3-C), in which the abstraction rates were significantly larger than other sites. For instance, the largest hydrogen abstraction rate is predicted to occur at a secondary carbon site (4-C). This could be explained by the electron donor effect of the carboxylate anion $\left(-\mathrm{COO}^{-}\right)$group in $\beta$-position when the $\mathrm{OH}$ attacks the reactive site as an electrophilic reaction (Monod and Doussin, 2008). A comparable rate is predicted for a tertiary carbon (3-C) as the adjacent $\alpha-\mathrm{CH}_{2}$ and $\beta-\mathrm{CH}_{3}$ groups exhibit significant electron donor properties. A large abstraction 
rate for 7-C could also be due to strong electron-donating effect of surrounding $\alpha$-CH groups. The model suggests a large difference in the $\mathrm{OH}$ reactivity for the three tertiary carbon sites (1-C, 3-C, and 5-C). For instance, the slowest abstraction rate is predicted for 5-C. This could attribute to a combined effect of the resonance electron-withdrawing effect of the $\alpha$-carboxylate anion $\left(-\mathrm{COO}^{-}\right)$ group and the field electron withdrawing effect of the $\beta-\mathrm{OH}$ group. The slow abstraction rate predicted for 1-C could be due to the field electron withdrawing effect of the $\beta-\mathrm{OH}$ group. In general, the $\mathrm{OH}$ reactivity for the primary carbons $(8-\mathrm{C}, 9-\mathrm{C}$, and 11-C) and hydroxyl group (10-O) were predicted to be slower than that of the secondary and tertiary carbons except 5-C. We would like to acknowledge that uncertainties could arise from that the sulfate group $\left(-\mathrm{OSO}_{3}{ }^{-}\right)$is currently not

10 being considered in the SAR model and differences between the concentrated aqueous aerosols and the SAR model that is formulated for dilute aqueous solutions. Other factors such as steric hindrance and long-distance electronic effects of the sulfate group $\left(-\mathrm{OSO}_{3}{ }^{-}\right)$on the reactivity have not been considered (Yamazaki et al., 2019) and are warranted for further studies.

Depending on the initial reaction site, a number of first-generation products with various structural isomers can be formed as indicated by multiple peaks observed in the EICs of detected ions (Fig. 2). Different isomers of second-generation products can also be formed from the reactions of $\mathrm{OH}$ with first-generation products. The possible formation pathways of detected products are further discussed below. Given a number of reaction pathways could possibly lead to the formation of the products with different isomers, only a general reaction scheme is depicted in Scheme 1 for simplicity and clarity.

\subsubsection{First-generation products}

$m / z=263\left(\mathrm{C}_{10} \mathrm{H}_{15} \mathrm{O}_{6} \mathrm{~S}^{-}\right)$: Upon oxidation, $\mathrm{C}_{10} \mathrm{H}_{15} \mathrm{O}_{6} \mathrm{~S}^{-}$is likely formed via an addition of a carbonyl functional group to $\alpha$ pOS-249 $\left(\mathrm{m} / z=249, \mathrm{C}_{10} \mathrm{H}_{17} \mathrm{O}_{5} \mathrm{~S}^{-}\right)$after the hydrogen abstraction by an $\mathrm{OH}$ radical from a primary or a secondary carbon instead of a tertiary carbon (Scheme 1). Depending on different initial reaction sites (4-C, 7-C, 8-C, 9-C, and 11-C), five structural isomers of $\mathrm{C}_{10} \mathrm{H}_{15} \mathrm{O}_{6} \mathrm{~S}^{-}$could be possibly formed from the cross-reactions of two $\mathrm{RO}_{2} \bullet$ via Bennett and Summers reactions (R1), Russell reactions (R2) and/or the reactions between an alkoxy radical with an $\mathrm{O}_{2}$ molecule $(\mathbf{R} 3)$.

$m / z=265\left(\mathrm{C}_{10} \mathrm{H}_{17} \mathrm{O}_{6} \mathrm{~S}^{-}\right): \mathrm{C}_{10} \mathrm{H}_{17} \mathrm{O}_{6} \mathrm{~S}^{-}$is likely formed via an addition of a hydroxyl functional group to $\alpha$ pOS-249 $\left(\mathrm{m} / z=249, \mathrm{C}_{10} \mathrm{H}_{17} \mathrm{O}_{5} \mathrm{~S}^{-}\right)$upon oxidation as shown in Scheme 1. The addition of a hydroxyl functional group to apOS-249 can possibly occur at all carbons, except the two 
total of eight isomers could be possibly formed from the cross-reactions of two $\mathrm{RO}_{2} \bullet$ via Russell reactions (R2), and the intermolecular hydrogen abstraction by alkoxy radicals (R4).

We also note that a product ion at $m / z=247\left(\mathrm{C}_{10} \mathrm{H}_{15} \mathrm{O}_{5} \mathrm{~S}^{-}\right)$was detected after oxidation

5 (Fig. 2). One possibility is that this product might be originated from the transformation of $\mathrm{C}_{10} \mathrm{H}_{17} \mathrm{O}_{6} \mathrm{~S}^{-}(m / z=265)$. Scheme $\mathbf{S} 2$ (Path a) shows that when the hydrogen abstraction occurs at the 1-C, the Pinacol rearrangement of vicinal diols involving a methyl shift and a loss of $\mathrm{H}_{2} \mathrm{O}$ could be a possible formation pathway (Bruice et al., 2004). This reaction occurs efficiently under acidic conditions and might not be favorable in this study since apOS-249 aerosols are expected to be neutral. Another possible pathway involves the isomerization of a hydroxyl alkyl radical with a ring opening, as shown in Scheme S2 (Path b). This reaction has been found to be efficient for gas-phase reactions between $\alpha$-pinene and $\mathrm{OH}$ radicals (Bergh et al., 2000; Peeters et al., 2001). Subsequent reactions of the hydroxyl alkyl radical could lead to the formation of $m / z=247$ $\left(\mathrm{C}_{10} \mathrm{H}_{15} \mathrm{O}_{5} \mathrm{~S}^{-}\right)$through the $\mathrm{HO}_{2}$ elimination processes. However, the significance of this reaction in aerosol-phase requires further investigation.

\subsubsection{Second-generation products}

As shown in Fig. 2, second-generation products with different isomers are formed through an addition of a carbonyl or a hydroxyl functional group to first-generation products upon oxidation.

20 For instance, as shown in Scheme 1, $\mathrm{C}_{10} \mathrm{H}_{17} \mathrm{O}_{7} \mathrm{~S}^{-}(m / z=281)$ can be formed from the further oxidation of $\mathrm{C}_{10} \mathrm{H}_{17} \mathrm{O}_{6} \mathrm{~S}^{-}(\mathrm{m} / z=265)$ with an addition of a hydroxyl functional group via $\mathbf{R} 2$ and R4. $\mathrm{C}_{10} \mathrm{H}_{13} \mathrm{O}_{7} \mathrm{~S}^{-}(m / z=277)$ can be formed from the oxidation of $\mathrm{C}_{10} \mathrm{H}_{15} \mathrm{O}_{6} \mathrm{~S}^{-}(\mathrm{m} / z=263)$ with an addition of a carbonyl functional group via R1-R3. Multiple pathways could potentially lead to the formation of $\mathrm{C}_{10} \mathrm{H}_{15} \mathrm{O}_{7} \mathrm{~S}^{-}(m / z=279)$. For instance, $\mathrm{C}_{10} \mathrm{H}_{15} \mathrm{O}_{7} \mathrm{~S}^{-}(m / z=279)$ can be formed through

25 the addition of a hydroxyl functional group to $\mathrm{C}_{10} \mathrm{H}_{15} \mathrm{O}_{6} \mathrm{~S}^{-}(m / z=263)$ via $\mathbf{R} 2$ and $\mathbf{R} 4$ and/or the addition of a carbonyl functional group to $\mathrm{C}_{10} \mathrm{H}_{17} \mathrm{O}_{6} \mathrm{~S}^{-}(m / z=265)$ via R1-R3.

We note that smaller products and small OSs $(\mathrm{C}<10)$ were not observed in the mass spectra and ion chromatograms. We do not have a clear explanation yet, but postulate that upon $\mathrm{OH}$ 30 oxidation of apOS-249, the self/cross-reactions of peroxy radicals with a cyclic structure tend to form stable products rather than alkoxy radicals. For instance, in a theoretical study by Capouet et al. (2004), a smaller branching ratio (0.3) was assigned to alkoxy radical formation in the disproportionation reactions of cyclic peroxy radicals ( 0.7 is assigned for acyclic peroxy radicals) to reproduce the formation of reaction products during the photooxidation of $\alpha$-pinene by $\mathrm{OH}$

35 radical. Rowley et al. (1992) also reported a low value (0.24) for alkoxy radical formation from the self-reactions of cyclohexylperoxy radicals. Another possible explanation is that a higher activation energy is estimated for the decomposition of an alkoxy radical when it is attached to larger ring 
structures (Wilsey et al., 1999). Altogether, the formation and decomposition of alkoxy radicals might be likely hindered, which may partly explain the insignificant formation of fragmentation products including small OSs $(\mathrm{C}<10)$ and inorganic sulfates (Sect. 3.4) upon OH oxidation of apOS-249. This might also suggest that more oxygenated $\mathrm{C}_{10}$ OSs $\left(\mathrm{C}_{10} \mathrm{H}_{15} \mathrm{O}_{7} \mathrm{~S}^{-}(\mathrm{m} / z=279)\right.$ and $\left.\mathrm{C}_{10} \mathrm{H}_{17} \mathrm{O}_{7} \mathrm{~S}^{-}(\mathrm{m} / z=281)\right)$ are more likely originated from further $\mathrm{OH}$ oxidation of first-generation products (Scheme 1) without fragmentation processes. For instance, as shown in Scheme S3, $\mathrm{C}_{10} \mathrm{H}_{15} \mathrm{O}_{7} \mathrm{~S}^{-}(m / z=279)$ and $\mathrm{C}_{10} \mathrm{H}_{17} \mathrm{O}_{7} \mathrm{~S}^{-}(m / z=281)$ could be formed through a $\mathrm{C}-\mathrm{C}$ bond cleavage of $\mathrm{RO} \bullet$ with a ring opening. The resulted carbonyl alkyl radical could undergo subsequent reactions, leading to the formation of $\mathrm{C}_{10} \mathrm{H}_{15} \mathrm{O}_{7} \mathrm{~S}^{-}(m / z=279)$ via the addition of a carbonyl group and

$10 \mathrm{C}_{10} \mathrm{H}_{17} \mathrm{O}_{7} \mathrm{~S}^{-}(\mathrm{m} / \mathrm{z}=281)$ via the addition of a hydroxyl group. However, these fragmentation reactions are expected to be not significant. Further laboratory and modeling investigations are required to better understand the fates of peroxy and alkoxy radicals with varying structures in different phases (i.e. gas phase vs. aerosol phase) and subsequent formation of reaction products (e.g. smaller OSs) upon oxidation.

\subsection{Heterogeneous OH Oxidation of apOS-249 - A Potential Source of Ambient OSs?}

On the basis of reaction products, we attempt to examine whether the heterogeneous $\mathrm{OH}$ oxidation of apOS-249 freshly formed from the photooxidation of $\alpha$-pinene could explain the formation of OSs detected in laboratory generated $\alpha$-pinene SOA and ambient aerosols. As shown in Table 2, five out of six product ions $(\mathrm{m} / \mathrm{z}=247,263,265,279$, and 281) have been detected in ambient aerosols (Iinuma et al., 2005; Surratt et al., 2008; Ma et al., 2014; Hettiyadura et al., 2019; Wang et al., 2021) while four out of six product ions $(\mathrm{m} / \mathrm{z}=247,265,279$, and 281) have been observed for SOA formed from the photooxidation of $\alpha$-pinene in the presence of acidic sulfate aerosols in laboratory studies (Liggio et al., 2006; Surratt et al., 2008; Ma et al., 2014; Zhang et al.,

25 2015; Hettiyadura et al., 2019). Reaction mechanisms have been proposed for the formation of some of these products such as $m / z=265\left(\mathrm{C}_{10} \mathrm{H}_{17} \mathrm{O}_{6} \mathrm{~S}^{-}\right)$and $279\left(\mathrm{C}_{10} \mathrm{H}_{15} \mathrm{O}_{7} \mathrm{~S}^{-}\right)$in the literature. For instance, in chamber studies, Liggio et al. (2006) suggested that $\mathrm{C}_{10} \mathrm{H}_{17} \mathrm{O}_{6} \mathrm{~S}^{-}(\mathrm{m} / z=265)$ can be formed through the reactive uptake of pinonaldehyde, a major semi-volatile product generated from $\alpha$-pinene oxidation, onto acidic sulfate aerosols via sulfate esterification reactions. Similar to

$30 \mathrm{C}_{10} \mathrm{H}_{17} \mathrm{O}_{6} \mathrm{~S}^{-}(\mathrm{m} / \mathrm{z}=265), \mathrm{C}_{10} \mathrm{H}_{15} \mathrm{O}_{7} \mathrm{~S}^{-}(\mathrm{m} / \mathrm{z}=279)$ can be produced through the reactive uptake of hydroxypinoinc acid on acidic sulfate aerosols via sulfate esterification reactions (Surratt et al., $2008)$. For field studies, ions corresponding to $m / z=247\left(\mathrm{C}_{10} \mathrm{H}_{15} \mathrm{O}_{5} \mathrm{~S}^{-}\right)$and $263\left(\mathrm{C}_{10} \mathrm{H}_{15} \mathrm{O}_{6} \mathrm{~S}^{-}\right)$have been observed in ambient aerosols, but their sources and formation mechanisms have remained unclear. Here, we show that these OSs previously observed in ambient aerosols and $\alpha$-pinene derived SOA in laboratory studies could be first- and/or second-generation products formed upon heterogeneous $\mathrm{OH}$ oxidation of apOS-249. 


\subsection{Formation of Inorganic Sulfate upon Oxidation}

Recent studies have reported that heterogeneous $\mathrm{OH}$ oxidation of small OSs $\left(\mathrm{C}_{1}, \mathrm{C}_{2}\right.$, and $\left.\mathrm{C}_{5}\right)$ can produce inorganic sulfates (Kwong et al., 2018; Lam et al., 2019; Chen et al., 2020; Xu et al., 2020a). It has been proposed that the decomposition of an alkoxy radical formed at the $\alpha$-position of the sulfate group can generate a sulfate radical anion $\left(\mathrm{SO}_{4}{ }^{-}\right)$, which subsequently reacts further to generate inorganic sulfur species $\left(\mathrm{HSO}_{4}{ }^{-}\right.$and $\mathrm{SO}_{4}{ }^{2-}$ ) (Scheme 1 and Scheme S3). We here examine the significance of this conversion from organosulfur to inorganic sulfur upon heterogeneous $\mathrm{OH}$ oxidation of $\alpha$ pOS-249 (a $\mathrm{C}_{10} \mathrm{OS}$ ). Fig. $\mathbf{S 3}$ shows the IC chromatograms of apOS-249 before and after heterogenous OH oxidation. Before oxidation (Fig. S3a), a small quan-

10 tity of $\mathrm{SO}_{4}{ }^{2-}$ (contributing only $1.9 \pm 1.3 \%$ of total sulfur mass) was detected in the ion chromatogram due to the hydrolysis of apOS-249, which has been corrected for the determination of sulfate yield. After oxidation (Fig. S3b), an increase in the $\mathrm{SO}_{4}{ }^{2-}$ signal was observed, suggesting that some sulfur is being converted from its organic form (i.e. apOS-249) into its inorganic form $\left(\mathrm{HSO}_{4}{ }^{-}\right.$and/or $\left.\mathrm{SO}_{4}{ }^{2-}\right)$ upon $\mathrm{OH}$ oxidation. The amount of inorganic sulfur formed from oxidation was then quantified to calculate the yield, defined as the total number of moles of $\mathrm{HSO}_{4}{ }^{-}$and $\mathrm{SO}_{4}{ }^{2-}$ formed per mole of $\alpha$ pOS-249 reacted at a given $\mathrm{OH}$ exposure (Xu et al., 2020a):

$$
\text { Yield }=\frac{\Delta\left[\mathrm{SO}_{4}{ }^{2-}\right]}{\Delta[\mathrm{\alpha pOS} \mathrm{-249]}} \times 100 \%
$$

where the $\mathrm{SO}_{4}{ }^{2-}$ concentration was quantified by IC and the $\alpha$ pOS-249 concentration was determined by HPLC/ESI-QTRAP-MS before and after oxidation. As shown in Fig. 5, the yields from $3.5 \pm 11.3 \%$ at $\mathrm{OH}$ exposure of $4.8 \times 10^{11}$ molecules $\mathrm{cm}^{-3} \mathrm{~s}$ to $13.8 \pm 4.7 \%$ at $14.3 \times 10^{11}$ molecules $\mathrm{cm}^{-3} \mathrm{~s}$. The relatively large uncertainty at low $\mathrm{OH}$ exposures is mainly attributed to the small change in apOS-249 and $\mathrm{SO}_{4}{ }^{2-}$ concentrations at low $\mathrm{OH}$ exposures (The determination of uncertainties of the yield is given in Supporting Information). The small yields could be explained by that the hydrogen abstraction at 5-C is likely not favorable compared to other carbon sites upon $\mathrm{OH}$ oxidation of $\alpha$ POS-249 at the first place as predicted by the SAR model (Table S2). The generation of sulfate radical anions $\left(\mathrm{SO}_{4}{ }^{-}\right)$via the breakage of the $\mathrm{C}-\mathrm{O}$ bond in 5-C alkoxy radical and the further reaction of $\mathrm{SO}_{4}{ }^{--}$to generate inorganic sulfates might not be favorable (Scheme 1 and Scheme S3).

It is also worthwhile to note that upon oxidation, the decomposition of alkoxy radicals ( $\mathrm{RO} \bullet$ ) formed at 5-C would lead to $\mathrm{SO}_{4}{ }^{-}$and a fragmentation product. For instance, a $\mathrm{C}_{10}$ aldehyde product $\left(\mathrm{C}_{10} \mathrm{H}_{16} \mathrm{O}_{2}, m / z=167\right)$ can be formed (Scheme 1). The effective saturation vapor pressure, $\mathrm{C}^{*}$ of this product is estimated to be $2.27 \times 10^{5} \mu \mathrm{g} \mathrm{m}^{-3}$ based on its saturation vapor pressure (3.29 
Pa) predicted from EVAPORATION (Compernolle et al., 2011). The volatility of this product is found to be about 5 orders of magnitude larger than that of $\alpha$ pOS-249 $\left(\mathrm{C}^{*}=1.67 \mu \mathrm{g} \mathrm{m}^{-3}\right)$, which is estimated using a saturation vapor pressure $\left(7.96 \times 10^{-6} \mathrm{~Pa}\right)$ predicted by COSMOtherm (Hyttinen et al. 2020). Given its high volatility, this fragmentation product likely partitions back to the gas phase and has not been detected in our chemical analysis.

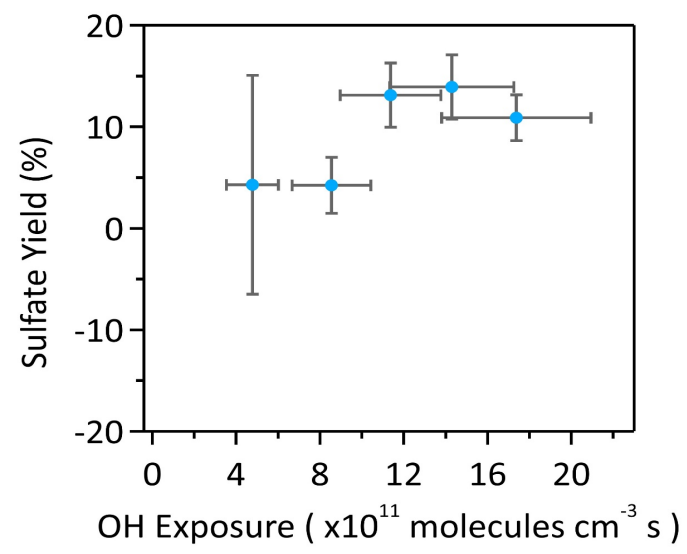

Figure 5. Molar yields of inorganic sulfur species $\left(\mathrm{HSO}_{4}{ }^{-}\right.$and $\left.\mathrm{SO}_{4}{ }^{2-}\right)$ as a function of $\mathrm{OH}$ exposure upon heterogeneous $\mathrm{OH}$ oxidation of $\alpha \mathrm{pOS}-249$. The x-error bars represent the uncertainties for $\mathrm{OH}$ exposures and y-error bars represent the uncertainties of derived molar yields (calculation details can be referred to Supporting Information).

\section{Atmospheric Implications}

To date, while the formation mechanisms of $\alpha$-pinene derived OSs have been investigated, its transformation pathways have remained unclear. Nonetheless, several laboratory studies have documented the chemical removal pathways of several OSs through oxidation, implying that certain OSs are not chemically stable and have the propensity for transformation to other organic or inorganic species via oxidation. In this work, we investigated the oxidative transformation process of apOS-249 via heterogeneous oxidation initiated by $\mathrm{OH}$ radicals. Kinetic data suggest that heterogeneous $\mathrm{OH}$ oxidation is a competitive sink for apOS-249. Oxidation reactions

20 dominantly involve the addition of hydroxyl and carbonyl functional groups, which increases the functionalities and oxygen content of apOS-249 during multigenerational oxidation steps. The formation of fragmentation products such as inorganic sulfates and smaller OSs was found to be insignificant. All these results indicate that $\alpha$ pOS-249s and other OSs may not be chemically stable in the atmosphere and can be continuously transformed once formed in the atmosphere. In

25 particular, heterogeneous OH oxidation of OSs could yield some previously unexplained OSs that are detected in atmospheric aerosols. We also acknowledge that the small yields reported for apOS249 are different from our previous studies that a significant amount of inorganic sulfates (yield 
$60 \%$ ) was formed upon heterogeneous $\mathrm{OH}$ oxidation of a small OS (i.e. methylsulfate, $\mathrm{CH}_{3} \mathrm{SO}_{4}^{-}$) (Kwong et al., 2018; Xu et al., 2020a). This might be attributed to that for the OH reaction with methylsulfate, only a few hydrogen atoms are available for the abstraction. The formation and decomposition of an alkoxy radical formed at the $\alpha$-position of the sulfate group are more likely occurred, leading to sulfate radical anion $\left(\mathrm{SO}_{4}{ }^{--}\right)$and subsequently inorganic sulfates. These results reveal that the sulfur conversion from its organic form (i.e. OSs) to inorganic form (i.e. inorganic sulfates) upon oxidation could be sensitive to the molecular structure of OSs (e.g. carbon chain length and functionality). Future investigations are needed to better elucidate the formation and isomer distribution of multigenerational functionalization and fragmentation products formed upon

10 oxidation. Lastly, smaller products and smaller OSs $(\mathrm{C}<10)$ were not detected upon oxidation of apOS-249. Future investigations are desired to investigate whether the chemical transformation and ageing of larger OSs could be the sources of smaller OSs in the atmosphere through various atmospheric processes. Overall, the findings of this work provide an improved understanding of the sources, fates and transformations of ambient OSs.

Data availability. Data are available upon request from the corresponding author.

Author contributions. Rongshuang Xu and Man Nin Chan designed the experiments. Rongshuang $\mathrm{Xu}$ and Sze In Madeleine Ng ran the experiments. Yuchen Wang provided the synthesized apOS-

20249 standard. Wing Sze Chow, Yee Ka Wong, Zhongping Yao, Pui-Kin So, and Jian Zhen Yu helped with the chemical analysis. Yuchen Wang and Jian Zhen Yu contributed to the formulation of the reaction mechanisms. Rongshuang Xu, Sze In Madeleine Ng, and Man Nin Chan prepared the manuscript. Jian Zhen Yu and Man Nin Chan edited the manuscript. All authors provided comments and suggestions for the manuscript.

Competing interests. The contact authors have declared that neither they nor their co-authors have any competing interests.

Acknowledgements. This work is supported by the Hong Kong Research Grants Council (1430011 and 16304519).

\section{References}

Bahl A. (Eds. 4th): Advanced Organic Chemistry, S. Chand Publication, New Delhi, India, 2012. Bergh v. d., Vanhees V., I., de Boer, R., Compernolle, F., and Vinckier, C.: Identification of the oxidation products of the reaction between $\alpha$-pinene and hydroxyl radicals by gas and high-performance liquid chromatography with mass spectrometric detection, J. Chrom. A., 896, 135-148. https://doi.org/10.1016/s0021-9673(00)00680-4, 2000.

Brüggemann, M., Xu, R., Tilgner, A., Kwong, K. C., Mutzel, A., Poon, H. Y., Otto, T., Schaefer, T., Poulain, L., Chan, M. N., and Herrmann, H.: Organosulfates in ambient aerosol: state of 
knowledge and future research directions on formation, abundance, fate, and importance, Environ. Sci. Technol., 54, 3767-3782, https://doi.org/10.1021/acs.est.9b06751.s001, 2020.

Bruice, P. Y. (Eds. 6th): Organic chemistry, Pearson/Prentice Hall, New Jersey, 2004.

Budisulistiorini, S. H., Li, X., Bairai, S. T., Renfro, J., Liu, Y., Liu, Y. J., McKinney, K. A., Martin, 5 S. T., McNeill, V. F., Pye, H. O. T., Nenes, A., Neff, M. E., Stone, E. A., Mueller, S., Knote, C., Shaw, S. L., Zhang, Z., Gold, A., and Surratt, J. D.: Examining the effects of anthropogenic emissions on isoprene-derived secondary organic aerosol formation during the 2013 Southern Oxidant and Aerosol Study (SOAS) at the Look Rock, Tennessee ground site, Atmos. Chem. Phys., 15, 8871-8888, https://doi.org/10.5194/acp-15-8871-2015, 2015.

10 Capouet, M., Peeters, J., Nozi`ere, B., and Müller, J.-F.: Alpha-pinene oxidation by OH: simulations of laboratory experiments, Atmos. Chem. Phys., 4, 2285-2311, https://doi.org/10.5194/acp-4-2285-2004, 2004.

Carrasquillo A. J., Daumit K. E., Kroll J. H.: Radical reactivity in the condensed phase: intermolecular versus intramolecular reactions of alkoxy radicals, J. Phys. Chem. Letters., 6, 2388-

15 2392, https://doi.org/10.1021/acs.jpclett.5b00913, 2015.

Chan, M. N., Surratt, J. D., Claeys, M., Edgerton, E. S., Tanner, R. L., Shaw, S. L., Zheng, M., Knipping, E. M., Eddingsaas, N. C., Wennberg, P. O., and Seinfeld, J. H.: Characterization and quantification of isoprene-derived epoxydiols in ambient aerosol in the southeastern United States, Environ. Sci. Technol., 44, 4590-4596, https://doi.org/10.1021/es100596b, 2010.

20 Chen, Y., Zhang, Y., Lambe, A. T., Xu, R., Lei, Z., Olson, N. E., Zhang, Z., Szalkowski, T., Cui, T., Vizuete, W., Gold, A., Turpin, B. J., Ault, A. P., Chan, M. N., and Surratt, J. D.: Heterogeneous hydroxyl radical oxidation of isoprene-epoxydiol-derived methyltetrol sulfates: plausible formation mechanisms of previously unexplained organosulfates in ambient fine aerosols, Environ. Sci. Technol. Letters, 7, 460-468, https://doi.org/10.1021/acs.estlett.0c00276.s001, 2020.

25 Compernolle, S., Ceulemans, K., and Müller, J.-F.: EVAPORATION: A new vapour pressure estimation method for organic molecules including non-additivity and intramolecular interactions, Atmos. Chem. Phys., 11, 9431-9450, https://doi.org/10.5194/acp-11-9431-2011, 2011.

Craig, R. L., Peterson, P. K., Nandy, L., Lei, Z., Hossain, M. A., Camarena, S., Dodson, R. A., Cook, R. D., Dutcher, C. S., and Ault, A. P.: Direct determination of aerosol pH: size-resolved

30 measurements of submicrometer and supermicrometer aqueous particles, Anal. Chem., 90, 1123211239. https://doi.org/10.1021/acs.analchem.8b00586, 2018.

Darer, A. I., Cole-Filipiak, N. C., O’Connor, A. E., and Elrod, M. J.: Formation and stability of atmospherically relevant isoprene-derived organosulfates and organonitrates, Environ. Sci. Technol., 45, 1895-1902, https://doi.org/10.1021/es103797z, 2011.

35 Domingos J S.S., Regis C. D., Santos V.S., Andrade B., and Rocha O.: A comprehensive and suitable method for determining major ions from atmospheric particulate matter matrices, J. Chrom. A., 1266, 17-23, https://doi.org/10.1016/j.chroma.2012.08.074, 2012.

Freedman, M. A., Ott E.-J. E., and Marak K. E.: Role of pH in aerosol processes and measurement challenges, J. Phys. Chem. A., 123, 1275-1284, https://doi.org/10.1021/acs.jpca.8b10676, 2019.

40 George, I. J. and Abbatt, J. P. D.: Heterogeneous oxidation of atmospheric aerosol particles by gasphase radicals, Nat. Chem., 2, 713-722, https://doi.org/10.1038/nchem.806, 2010.

Guenther, A. B., Jiang, X., Heald, C. L., Sakulyanontvittaya, T., Duhl, T., Emmons, L. K., and Wang, X.: The Model of Emissions of Gases and Aerosols from Nature version 2.1 (MEGAN2.1): an extended and updated framework for modeling biogenic emissions, Geosci. Model Dev., 5, 45 1471-1492, https://doi.org/10.5194/gmd-5-1471-2012, 2012.

Hansen, A. M. K., Hong, J., Raatikainen, T., Kristensen, K., Ylisirnio, A., Virtanen, A., Petaja, T., Glasius, M., and Prisle, N. L.: Hygroscopic properties and cloud condensation nuclei activation of limonene-derived organosulfates and their mixtures with ammonium sulfate, Atmos. Chem. Phys., 15, 14071-14089. https://doi.org/10.5194/acp-15-14071-2015, 2015. 
Hettiyadura, A. P. S., Al-Naiema, I. M., Hughes, D. D., Fang, T., and Stone, E. A.: Organosulfates in Atlanta, Georgia: anthropogenic influences on biogenic secondary organic aerosol formation, Atmos. Chem. Phys., 19, 3191-3206, https://doi.org/10.5194/acp-19-3191-2019, 2019.

Hettiyadura, A. P. S., Jayarathne, T., Baumann, K., Goldstein, A. H., de Gouw, J. A., Koss, A.,

5 Keutsch, F. N., Skog, K., and Stone, E. A.: Qualitative and quantitative analysis of atmospheric organosulfates in Centreville, Alabamam, Atmos. Chem. Phys., 17, 1343-1359, 10.5194/acp-171343-2017, 2017.

Hu, K. S., Darer, A. I., Elrod, M. J. Thermodynamics and kinetics of the hydrolysis of atmospherically relevant organonitrates and organosulfates, Atmos. Chem. Phys., 11, 8307-8320, https://doi.org/10.5194/acp-11-8307-2011, 2011.

Huang, D. D., Li, Y. J., Lee, B. P., and Chan, C. K.: Analysis of organic sulfur compounds in atmospheric aerosols at the HKUST supersite in Hong Kong using HR-ToF-AMS, Environ. Sci. Technol., 49, 3672-3679, https://doi.org/10.1021/es5056269, 2015.

Huang, R.-J., Cao, J., Chen, Y., Yang, L., Shen, J., You, Q., Wang, K., Lin, C., Xu, W., Gao, B.,

15 Li, Y., Chen, Q., Hoffmann, T., O'Dowd, C. D., Bilde, M., and Glasius, M.: Organosulfates in atmospheric aerosol: synthesis and quantitative analysis of PM2.5 from Xi'an, Northwestern China, Atmos. Meas. Tech., 11, 3447-3456. https://doi.org/10.5194/amt-11-3447-2018, 2018.

Hughes, D. D. and Stone, E. A.: Organosulfates in the Midwestern United States: Abundance, composition and stability, Environ. Chem., 16, 312-322, https://doi.org/10.1071/EN18260, 2019.

20 Hyttinen, N., Elm, J., Malila, J., Calderón, S. M., and Prisle, N. L.: Thermodynamic properties of isoprene- and monoterpene-derived organosulfates estimated with COSMOtherm, Atmos. Chem. Phys., 20, 5679-5696, https://doi.org/10.5194/acp-20-5679-2020, 2020.

Iinuma, Y., Böge, O., Miao, Y., Sierau, B., Gnauk, T., and Herrmann, H.: Laboratory studies on secondary organic aerosol formation from terpenes, Faraday Discuss., 130, 279-294, 25 https://doi.org/10.1039/b502160j, 2005.

Iinuma, Y., Müller, C., Berndt, T., Böge, O., Claeys, M., and Herrmann, H.: Evidence for the existence of organosulfates from $\beta$-pinene ozonolysis in ambient secondary organic aerosol, Environ. Sci. Technol., 41, 6678-6683, https://doi.org/10.1021/es070938t, 2007.

Kanakidou, M., Seinfeld, J. H., Pandis, S. N., Barnes, I., Dentener, F. J., Facchini, M. C., Dingenen,

30 R. V., Ervens, B., Nenes, A., Nielsen, C. J., Swietlicki, E., Putaud, J. P., Balkanski, Y., Fuzzi, S., Horth, J., Moortgat, G. K., Winterhalter, R., Myhre, C. E. L., Tsigaridis, K., Vignati, E., Stephanou, E. G., and Wilson, J.: Organic aerosol and global climate modelling: a review, Atmos. Chem. Phys., 5, 1053-1123, https://doi.org/10.5194/acp-5-1053-2005, 2005.

Kang, E., Root, M. J., Toohey, D. W., and Brune, W. H.: Introducing the concept of Potential

35 Aerosol Mass (PAM), Atmos. Chem. Phys, 7, 5727-5744, https://doi.org/10.5194/acp-7-57272007, 2007.

Kristensen, K., and Glasius, M.: Organosulfates and oxidation products from biogenic hydrocarbons in fine aerosols from a forest in Northwest Europe during spring, Atmos. Environ., 45, 4546-4556, https://doi.org/10.1016/j.atmosenv.2011.05.063, 2011.

40 Kroll, J., Lim, C., Kessler, S., and Wilson, K.: Heterogeneous oxidation of atmospheric organic aerosol: kinetics of changes to the amount and oxidation state of particle-phase organic carbon, $\mathrm{J}$. Phys. Chem. A., 119, 10767-10783, https://doi.org:10.1021/acs.jpca.5b06946, 2015.

Kwong, K. C., Chim, M. M., Davies, J. F., Wilson, K. R., and Chan, M. N.: Importance of sulfate radical anion formation and chemistry in heterogeneous oh oxidation of sodium methyl sulfate, the

45 smallest organosulfate, Atmos. Chem. Phys., 18, 2809-2820, https://doi.org:10.5194/acp-18-28092018, 2018.

Lam, H. K., Xu, R., Choczynski, J., Davies, J. F., Ham, D., Song, M., Zuend, A., Li, W., Tse, Y.L. S., and Chan, M. N.: Effects of liquid-liquid phase separation and relative humidity on the heterogeneous oh oxidation of inorganic-organic aerosols: insights from methylglutaric 
acid/ammonium sulfate particles, Atmos. Chem. Phys., 21, 2053-2066, https://doi.org:10.5194/acp-21-2053-2021, 2021.

Lam, H. K., Kwong, K. C., Poon, H. Y., Davies, J. F., Zhang, Z., Gold, A., Surratt, J. D., and Chan, M. N.: Heterogeneous $\mathrm{OH}$ oxidation of isoprene-epoxydiol-derived organosulfates: kinetics,

5 chemistry and formation of inorganic sulfate, Atmos. Chem. Phys., 19, 2433-2440, https://doi.org:10.5194/acp-19-2433-2019, 2019.

Liggio, J., and Li, S.-M.: Organosulfate Formation during the uptake of pinonaldehyde on acidic sulfate aerosols, Geophys. Res. Lett., 33, L13808, https://doi.org:10.1029/2006g1026079, 2006.

Ma, Y., Xu, X., Song, W., Geng, F., and Wang, L.: Seasonal and Diurnal Variations of Particulate

10 Organosulfates in Urban Shanghai, China, Atmos. Environ., 85, 152-160, https://doi.org:10.1016/j.atmosenv.2013.12.017, 2014.

Monod A., and Doussin J.F.: Structure-activity relationship for the estimation of OH-oxidation rate constants of aliphatic organic compounds in the aqueous phase: alkanes, alcohols, organic acids and bases, Atmos. Environ., 42, 7611-7622, https://doi.org:10.1016/j.atmosenv.2008.06.005, 2008.

Pye, H. O. T., Chan, A. W. H., Barkley, M. P., and Seinfeld, J. H.: Global modeling of organic aerosol: the importance of reactive nitrogen (NOx and $\left.\mathrm{NO}_{3}\right)$, Atmos. Chem. Phys., 10, $11261-$ 11276, https://doi.org/10.5194/acp-10-11261-2010, 2010.

Peeters, J., Vereecken, L., and Fantechi, G.: The detailed mechanism of the OH-initiated

20 atmospheric oxidation of $\alpha$-pinene: a theoretical study, Phys. Chem. Chem. Phys., 3, 5489-5504, https://doi.org/10.1039/b106555f, 2001.

Rowley D. M., Lightfoot P. D., Lesclaux R., and Wallington T. J.: Ultraviolet absorption spectrum and self-reaction of cyclopentylperoxy radicals, J. Chem. Soc., Faraday Trans., 88, 1369-1376, https://doi.org:10.1039/ft9928801369, 1992.

25 Riva, M., Tomaz, S., Cui, T. Q., Lin, Y. H., Perraudin, E., Gold, A., Stone, E. A., Villenave, E., and Surratt, J. D.: Evidence for an unrecognized secondary anthropogenic source of organosulfates and sulfonates: gas-phase oxidation of polycyclic aromatic hydrocarbons in the presence of sulfate aerosol, Environ. Sci. Technol., 49, 6654-6664, https://doi.org:10.1021/acs.est.5b00836, 2015.

Shakya, K. M., and Peltier, R. E.: Investigating missing sources of sulfur at Fairbanks, Alaska,

30 Environ. Sci. Technol., 47, 9332-9338, https://doi.org:10.1021/es402020b, 2013.

Shakya, K. M., and Peltier, R. E.: Non-sulfate sulfur in fine aerosols across the United States: insight for organosulfate prevalence, Atmos. Environ., 100, 159-166, https://doi.org:10.1016/j.atmosenv.2014.10.058, 2015.

Stone, E. A., Yang, L., Yu, L. E., and Rupakheti, M.: Characterization of Organosulfates in

35 Atmospheric Aerosols at Four Asian Locations, Atmos. Environ., 47, 323-329, https://doi.org:10.1016/j.atmosenv.2011.10.058, 2012.

Surratt, J. D., Gómez-González, Y., Chan, A. W. H., Vermeylen, R., Shahgholi, M., Kleindienst, T. E., Edney, E. O., Offenberg, J. H., Lewandowski, M., Jaoui, M., Maenhaut, W., Claeys, M., Flagan, R. C., and Seinfeld, J. H.: Organosulfate formation in biogenic secondary organic aerosol,

40 J. Phys. Chem. A., 112, 8345-8378, https://doi.org:10.1021/jp802310p, 2008.

Surratt, J. D., Kroll, J. H., Kleindienst, T. E., Edney, E. O., Claeys, M., Sorooshian, A., Ng, N. L., Offenberg, J. H., Lewandowski, M., Jaoui, M., Flagan, R. C., and Seinfeld, J. H.: Evidence for organosulfates in secondary organic aerosol, Environ. Sci. Technol., 41, 517-527, https://doi.org:10.1021/es070938t, 2007.

45 Tolocka, M. P., and Turpin, B.: Contribution of organosulfur compounds to organic aerosol mass, Environ. Sci. Technol., 46, 7978-7983, https://doi.org:10.1021/es300651v, 2012.

Vogel, A. L., Schneider, J., Müller-Tautges, C., Klimach, T., and Hoffmann, T.: Aerosol chemistry resolved by mass spectrometry: insights into particle growth after ambient particle formation, Environ. Sci. Technol., 50, 10814-10822, https://doi.org:10.1021/acs.est.6b01673, 2016. 
Wang, Y., Zhao, Y., Wang, Y., Yu, J. Z., Shao, J., Liu, P., Zhu, W., Cheng, Z., Li, Z., Yan, N., and Xiao, H.: Organosulfates in atmospheric aerosols in Shanghai, China: seasonal and interannual variability, origin, and formation mechanisms, Atmos. Chem. Phys., 21, 2959-2980, https://doi.org:10.5194/acp-21-2959-2021, 2021.

5 Wang, Y., Hu, M., Guo, S., Wang, Y., Zheng, J., Yang, Y., Zhu, W., Tang, R., Li, X., Liu, Y., Le Breton, M., Du, Z., Shang, D., Wu, Y., Wu, Z., Song, Y., Lou, S., Hallquist, M., and Yu, J.: The secondary formation of organosulfates under interactions between biogenic emissions and anthropogenic pollutants in summer in Beijing, Atmos. Chem. Phys., 18, 10693-10713, https://doi.org:10.5194/acp-18-10693-2018, 2018.

10 Wang, Y., Ren, J., Huang, X. H. H., Tong, R., and Yu, J. Z.: Synthesis of four monoterpene-derived organosulfates and their quantification in atmospheric aerosol samples, Environ. Sci. Technol., 51, 6791-6801, https://doi.org:10.1021/acs.est.7b01179, 2017.

Weber, R., Guo, H., and Russell, A.: High aerosol acidity despite declining atmospheric sulfate concentrations over the past 15 years, Nat. Geosci., 9, 282-285, https://doi.org/10.1038/ngeo2665,

152016

Wilsey S., Dowd P., and Houk K. N.: Effect of alkyl substituents and ring size on alkoxy radical cleavage reactions, J. Organ. Chem., 64, 8801-8811, https://doi.org:10.1021/jo990652+, 1999.

Xu, R., Ge, Y., Kwong, K. C., Poon, H. Y., Wilson, K. R., Yu, J. Z., and Chan, M. N.: Inorganic sulfur species formed upon heterogeneous $\mathrm{OH}$ oxidation of organosulfates:

20 a case study of methyl sulfate, ACS Earth Space Chem., 4, 2041-2049, https://doi.org:10.1021/acsearthspacechem.0c00209, 2020a.

Xu, R., Lam, H. K., Wilson, K. R., Davies, J. F., Song, M., Li, W., Tse, Y.-L. S., and Chan, M. N.: Effect of inorganic-to-organic mass ratio on the heterogeneous $\mathrm{OH}$ reaction rates of erythritol: implications for atmospheric chemical stability of 2-methyltetrols, Atmos. Chem. Phys., 20, 38793893, https://doi.org/10.5194/acp-20-3879-2020, 2020b.

Yamazaki, Y., Naganuma, J., and Gotoh, H.: A Theoretical, dynamical evaluation method of the steric hindrance in nitroxide radicals using transition states of model reactions, Sci. Rep., 9, 20339. https://doi.org:10.1038/s41598-019-56342-w, 2019.

Zhang, H., Worton, D. R., Lewandowski, M., Ortega, J., Rubitschun, C. L., Park, J.-H., Kristensen,

30 K., Campuzano-Jost, P., Day, D. A., Jimenez, J. L., Jaoui, M., Offenberg, J. H., Kleindienst, T. E., Gilman, J., Kuster, W. C., de Gouw, J., Park, C., Schade, G. W., Frossard, A. A., Russell, L., Kaser, L., Jud, W., Hansel, A., Cappellin, L., Karl, T., Glasius, M., Guenther, A., Goldstein, A. H., Seinfeld, J. H., Gold, A., Kamens, R. M., and Surratt, J. D.: Organosulfates as tracers for Secondary Organic Aerosol (SOA) formation from 2-Methyl-3-Buten-2-ol (MBO) in the atmosphere, Environ. Sci. Technol., 46, 9437-9446. 10.1021/es301648z, 2012. 